\title{
Modeling and Prediction of the end of Life Vehicles Number Distribution in Serbia
}

\author{
Miroslav D. Sokić ${ }^{1}$, Ilija B. Ilić ${ }^{2}$, Vaso D. Manojlović ${ }^{1}$, Branislav \\ R. Marković ${ }^{1}$, Zvonko P. Gulišija ${ }^{1}$, Milan D. Pavlović ${ }^{3}$, Nada D. \\ Štrbac $^{4}$ \\ ${ }^{1}$ Institute for Technology of Nuclear and Other Mineral Raw Materials, 86 \\ Franchet d'Esperey Street, 11000 Belgrade, Serbia; m.sokic@itnms.ac.rs, \\ v.manojlovic@itnms.ac.rs, b.markovic@itnms.ac.rs, z.gulisija@itnms.ac.rs \\ ${ }^{2}$ Faculty of Technology and Metallurgy, University of Belgrade, Karnegijeva 4, \\ 11000 Belgrade, Serbia; miljan.ilic@ mbpvs.gov.rs \\ ${ }^{3}$ Technical Faculty "Mihajlo Pupin” in Zrenjanin, University of Novi Sad, Đure \\ Đakovića bb, 23000 Zrenjanin, Serbia, pmilan@sbb.rs \\ ${ }^{4}$ University of Belgrade, Technical Faculty, VJ 12, 19210 Bor, Serbia, \\ nstrbac@tf.bor.ac.rs
}

\begin{abstract}
The impact of various time-defendant factors on the recycling rate of end-of-life vehicles (ELV) in Republic of Serbia was investigated. Statistical distribution of the frequency of the number of ELV in the year of dismantling depending on the year of production of ELV is designed using the two-parameter Weibull distribution function and MATLAB software, based on a real time data. Obtaining the time-dependence of Weibull parameters, a statistical distribution of frequency of the number of ELV in the coming period in Serbia was simulated. These results in combination with amount of materials in the most abundant cars in Serbia were used to simulate the overall amount of materials, which are available for recycling, in the coming period. These results are essential for automotive recycling industry management, particularly for shredders, dismantlers and metal pre-processors.
\end{abstract}

Keywords: dynamic model; ELV; recycling; secondary raw materials; simulation

\section{Introduction}

Metallic secondary raw materials are generated from the industries that use metals. Different areas of application and the various methods of processing and use as structural materials leads to the formation of a very diverse scrap and/or waste material supply [1]. Industrial products include a variety of materials related 
to each other in various ways. After the end of the product life cycle, due to deterioration or technological obsolescence, they need to be recycled to the valuation of the material from which the product is made. EU legislation has defined the high standards and stringent environmental regulations [2], therefore, the recycling of various metallic secondary raw materials becomes inevitable [3]. However, after recycling, metals may lose their initial characteristics, both in terms of purity and in terms of mechanical properties. Hence, the recycled metallic materials are commonly used in less demanding applications. In order to minimize the losses of these materials due to contamination during the recycling process, it is essential to understand the relations between the technological processes of recycling and materials physical and chemical characteristics [4]. In the primary natural resources, metals in the mineral forms are bounded in the different ores. Exploitation and production of base metals is a complex series of a large number of technological processes adapted to the relevant type of ore. Obtained metals are incorporated into products which, after the expiration of the life cycle, become the amortization waste. The waste is collected, prepared for processing and sent to recycling streams, which are introduced in the production of metals as industrial recycling resources. Thus, metals find their way back to the source of the cycle and provide the basis of industrial cycles.

Modern society is regulated by extensive use of complex multi-component products, of which, vehicles are a typical example. They are composed of different materials, provided that the individual components are increasingly minimized, whether they are expensive, or have a detrimental effect on the function of the product. From an economic point of view, in practice, the complete disassembly of the product is unattractive and unprofitable. Therefore, partial disassembly, shredding, chopping and crushing are performed and thus prepared material returns to the basic resources of the system. However, with such a treatment and processing, the pure metal cannot be obtained, because there is contamination due to strong joints of different materials in the product and the imperfections of the processes of separation. As a result, the metal material contains impurities that are difficult to distinguish using the existing metallurgical processes [5]. The results are significant non-refundable losses and a less quality of metal obtained from secondary raw materials.

Automotive recycling infrastructure is related to:

- Dismantlers

- Shredders

- Operators of non-ferrous metals

The flow of materials within the automotive recycling infrastructure is shown in Fig. 1. 
Input

$\underline{\text { Output }}$

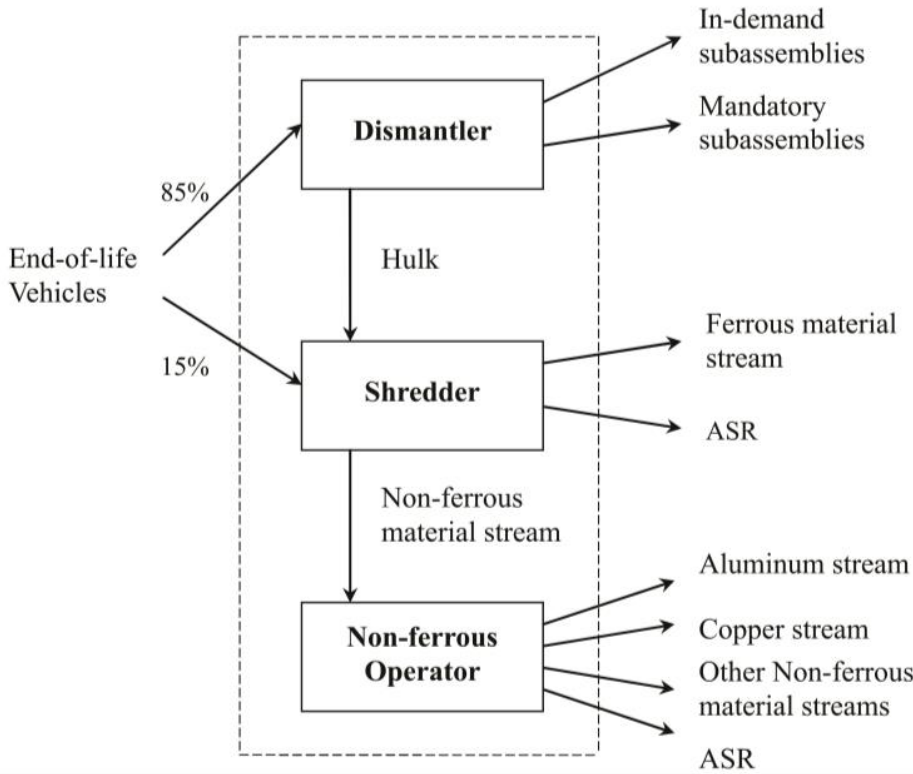

Figure 1

The materials flow of the ELV in the automotive recycling infrastructure [19]

Dismantlers remove parts from the car such as the engine, transmission, radiator, catalytic converter, petrol, fuel tank, fluids, tires, batteries and air bags because of their value or because of the Shredder requirements for their removal [6]. It is estimated that the content of non-metallic materials after disassembling is almost the same as before dismantling, because the parts removed by dismantlers are mainly based on metals. After removing the automotive parts, the car shell is sent to the shredder.

The shredding process enables the separation of the multicomponent materials by magnetic separation and by the methods based on differences in specific weight of materials. As shown in the diagram (Fig. 1), there are three main output streams of the shredding process: the stream of ferrous metals, the stream nonferrous metals, and the stream of automotive shredding residue (ASR). Ferrous metals, recycled by shredding process, are sold on the steelmaker market, non-ferrous metals are sold in the operators and non-ferrous metal market, and the shredder residue is deposited in the landfields $[7,8]$.

Operators of non-ferrous metals separate the stream of non-ferrous metals into different flows such as aluminum, copper and zinc.

A shredder plant with a capacity of 34000t/year for one shift, in the recycling center "Scholc"-Železnik in Belgrade, has successfully operated for many years. 


\section{Models for Monitoring the Impact of Various Parameters}

The influence of parameters such as the life cycle design, metal content and material combination within the vehicle on recyclability of the car is significant. Examination of these parameters and monitoring of their trends and changes is essential for the successful management of the major economic issues within the automotive industry.

In one study [9], assessment of material/components flow and economic exchange within the life cycle of the material in the automotive industry has been developed. Issues which were processed were:

- What could be the effect to increase the recycling of plastic?

- What could be the impact in a decline in car sales?

- What could happen if most parts of a vehicle are built of aluminum, plastic and ultra-light steel?

Isaacs and Gupta [10] developed optimization model to describe the impact of the vehicle with a high content of polymeric materials on the automotive recycling infrastructure. The aim of this study was to determine the optimal level of plastics which are needed to be removed, after the shredding process, to maintain the profitability of all business areas within the infrastructure. Using the same approach, two additional studies were conducted, one to determine the increasing effect of the materials content based on aluminum in vehicle on the infrastructure [11], and other to compare the impact of electronic vehicles, hybrid vehicles and vehicles with a high content of polymeric materials on the automotive recycling infrastructure $[12,13]$. Optimization is the ideal approach in decision making for a given scenario, but this approach requires a precise mathematical determination of constraints and objectives.

Zamudio [14] developed a dynamic model to describe the recycling of cars. This model does not take into account materials which are connected with the replacement of parts, as well as, dismantling process or economic concerns for that process. Also, in the flow of the materials the interdependence is not assumed, so that the flow of various materials (e.g. steel and aluminum) will never be analyzed separately. It was concluded that the existing automotive recycling infrastructure should be modified in order to resist changes in the market.

Several other models use a dynamic system, in order to characterize the material flow and economic exchange within the recycling infrastructure. To explain the impact of changes in the material composition of the vehicle on the sustainability of the economy and the environment within the automotive recycling infrastructure, Bandivadekar et al. [15] developed a simulation model for recovery and recycling of cars. This model describes the flow of materials and economic 
exchange of any business issue within the automotive recycling infrastructure. This model is then used to determine the profitability of each business issue due to a certain changes in the market and changes in the material composition of vehicles.

In another study based on a dynamic system, a strategy to meet the provisions of the EU ELV regarding recovery and recycling of materials was analyzed [16, 17, 18]. In the study, conducted by Kumar and Sutherland [19, 20], different technological strategies that can justify the effectiveness of the recovery of materials in the automotive recycling infrastructure were analyzed. The aim of their analysis was to determine the technological costs which could be related to the shredders and dismantlers used to achieve recovery of materials compared to those established in Europe.

Dynamic annual flow models, incorporating consumer discards and usage losses and featuring deterministic and stochastic end-of-cycle returns by the consumer, were developed for reused or remanufactured products, including fast/slow cycling and short/long-lived products [21].

In order to define the link between end-of-life products, their composition, and design a dynamic model was developed for cars [22, 23, 24]. This model permits the visualization of the influence of various parameters and distributions on the recycling rate over time. In addition, this model also permits the formulation of an improved definition of recycling rate. The architecture of the dynamic model, as shown in Fig. 2, will be used to capture the rapidly changing weight, composition, and lifetime of the car, which determine directly the recycling rate of vehicles. The final metal recovery depends on the prevalent thermodynamics and kinetics of the metallurgical processes, which are related to the material cycle [5]. Van Schaik and Reuter [24] showed that the recycling rate cannot be represented by an average or single value as required by EU legislation, but is largely dependent on the distributed nature and therefore the standard deviations of the time-varying lifetime, weight and composition of the car. The various simulations, using the dynamic system model, make clear that the weight and composition of the car at production and dismantling are determined by the different distributions and are highly dependent on their fluctuations. 


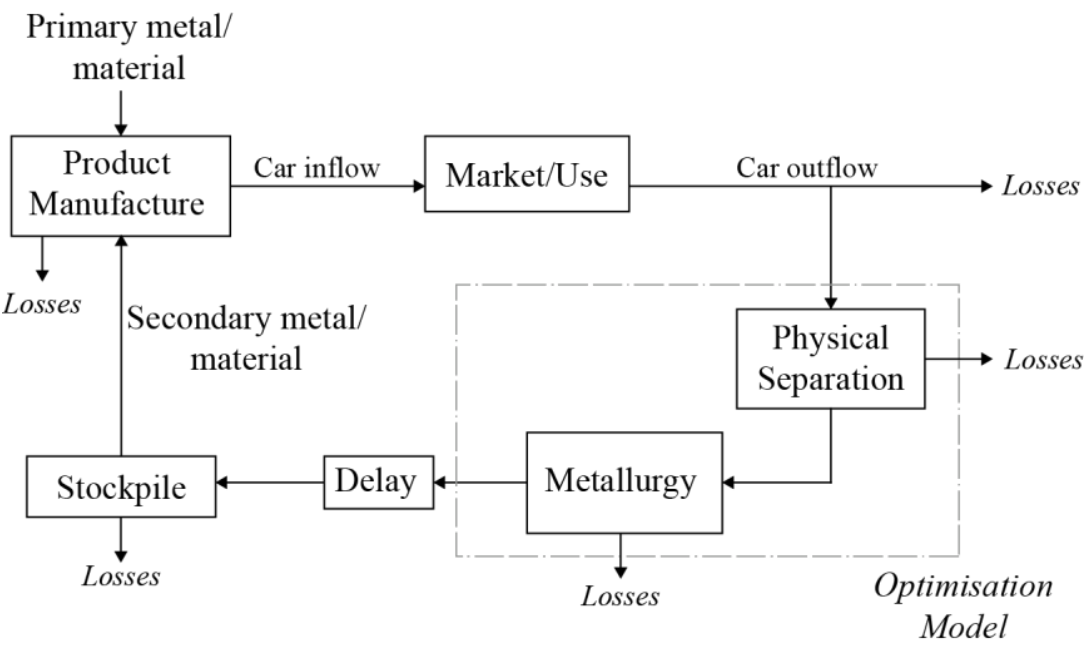

Figure 2

Scheme of the dynamic model [22]

It is estimated that in the Republic of Serbia, currently in use, are more than two million vehicles $(2,274,770$ vehicles in the year 2008, including trailers, tractors, commercial vehicles and motorcycles), whose average life cycle is between 18 and 19 years [25]. It is estimated that more than one million older vehicles, in various states of functioning, waiting to be recycled, and about 100,000 to 120,000 vehicles each year cannot be recycled, due to deterioration.

This state of the automotive recycling industry originated, primarily due to an unstable political and socio-economic situation in the country, in the period between 1990 and 2002. After 2002, the situation in the country significantly improved and was reflected in the automotive recycling industry. The dynamic model which describes the number of cars at the end of the life cycle, as well as, monitoring trends in the composition of the materials is of crucial importance for businesses within the automotive recycling industry. The model is crucial to properly plan processing capacity and to develop related business models that will ultimately lead to positive economic development and sustainability.

\section{Recycling of Cars - Simulation}

The statistical distribution of the number of cars on their end of life can be described by a normal distribution, depending on the year of production and year of dismantling of the cars (Fig. 3). These diagrams are constructed based on the number of cars that are available for recycling in a given year, along with the average age of the cars that are recycled in the same year. The diagrams were 
constructed using the software package MATLAB. The mean value of the number of cars, which are recycled in one year, can be approximated by the number of unregistered cars in the same year. The average number of unregistered cars in the period between 1994 and 2001 year is approximately 58000 cars per year, and approximately 64000 cars in the period between 2002 and 2008 year [25].

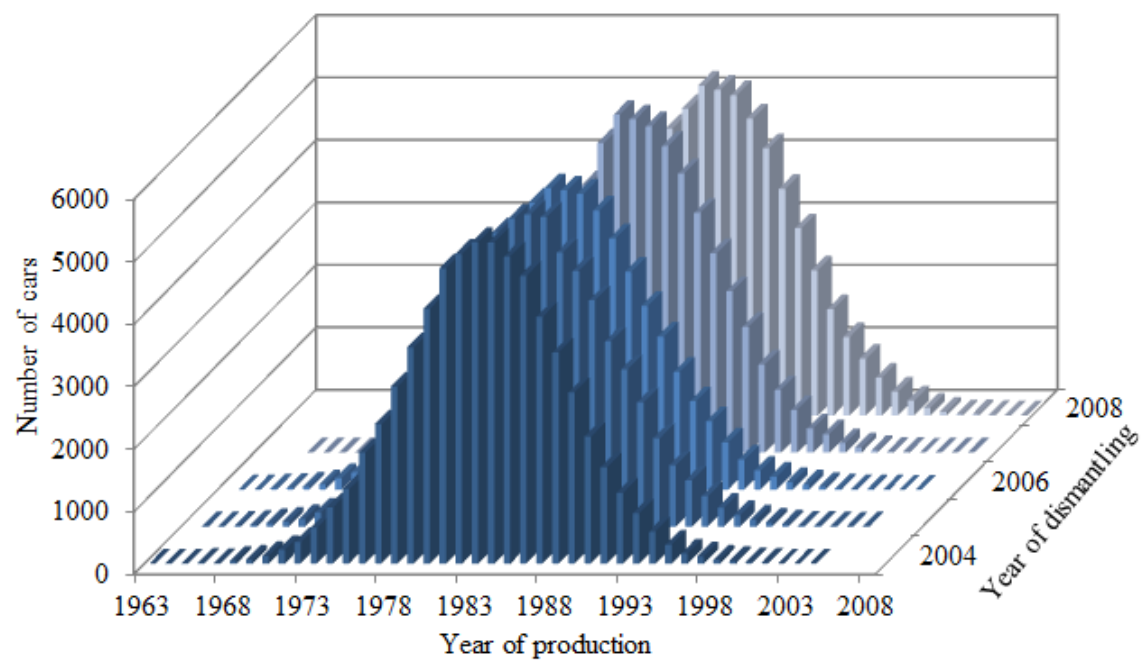

Figure 3

The normal distribution of the number of waste cars, by year of production and dismantling, in Serbia

The normal distribution curves in Fig. 3 can be described by the two-parameter Weibull distribution function:

$W(t)=\frac{a}{b^{a}} t^{a-1} \exp \left[-\left(\frac{t}{b}\right)^{a}\right]$

where (a) is the shape parameter, and (b) is the scale parameter, (a, b>0). The shape parameter, also known as the Weibull slope, gives the Weibull distribution its flexibility. The scale parameter determines the range of the distribution.

Fitting of the curves in Figure 3 with the Weibull distribution function is done by using the MATLAB software package, wherein the correlation coefficients from $\mathrm{R}$ $=0.99$ are obtained. Also distribution parameters (a) and (b) are determined, whereby the average value of the shape parameter is $a=4$, and the scaling parameter, (b) is shown in functional dependence over the time period (Fig. 4). When (b) is increased, while (a) is kept the same, the distribution gets stretched out to the right and its height decreases, while maintaining its shape (Fig. 3). 


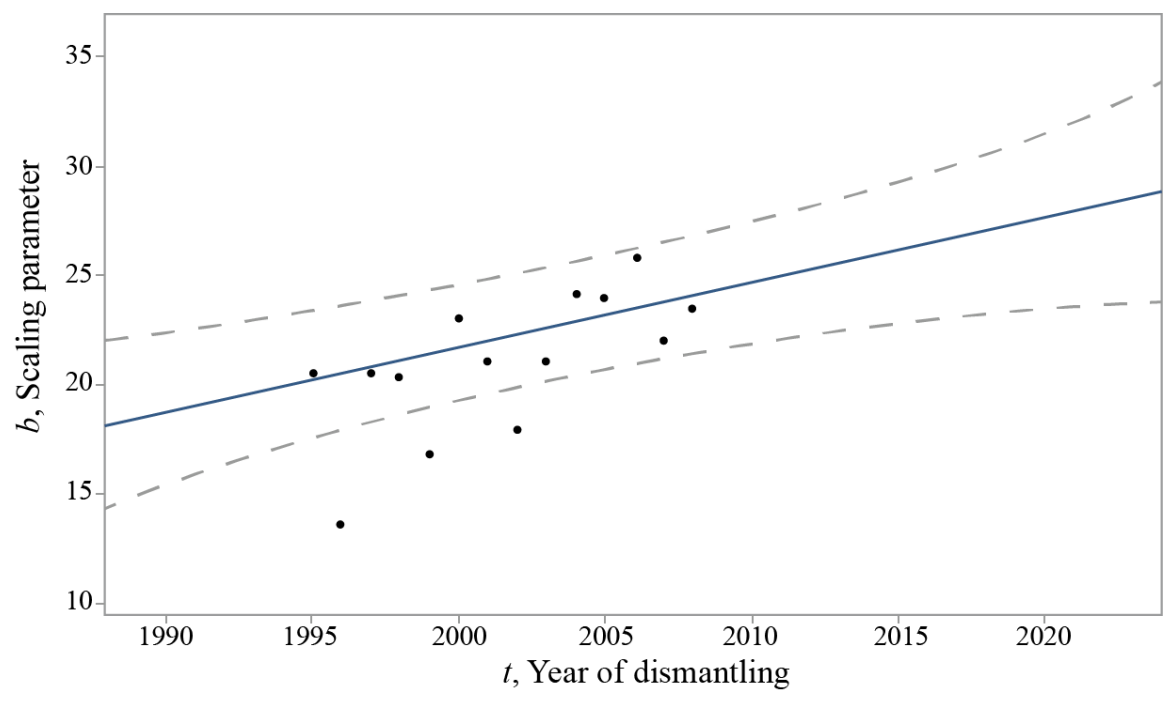

Figure 4

Dependence of the scaling parameter with the year of dismantling

The dependence of the scaling parameter (b) from the year disassembly (t) can be expressed by the following equation:

$b(t)=0,297 \cdot t-573$

The coefficients in the equation (2) were calculated with confidence limits of $95 \%$. Also, the prediction boundary of $95 \%$ was determined, which is shown with dashed lines in Figure 4. It should be noted that the values of the scaling parameter in 1996, 1999, 2002 years were rejected during determining of functional dependence. Major deviation of the parameter (b), in the aforementioned years, is attributed to the unstable socio-political situation in Serbia in those years.

The dependence of the parameter (b) from the time (Equation 2), together with the Weibull distribution function and the average dismantling year of ELV (Equation 1 ), are used in predicting the distribution of the number/frequency of the car that are recycled in the period between 2015 and 2025 year (Fig. 5). 


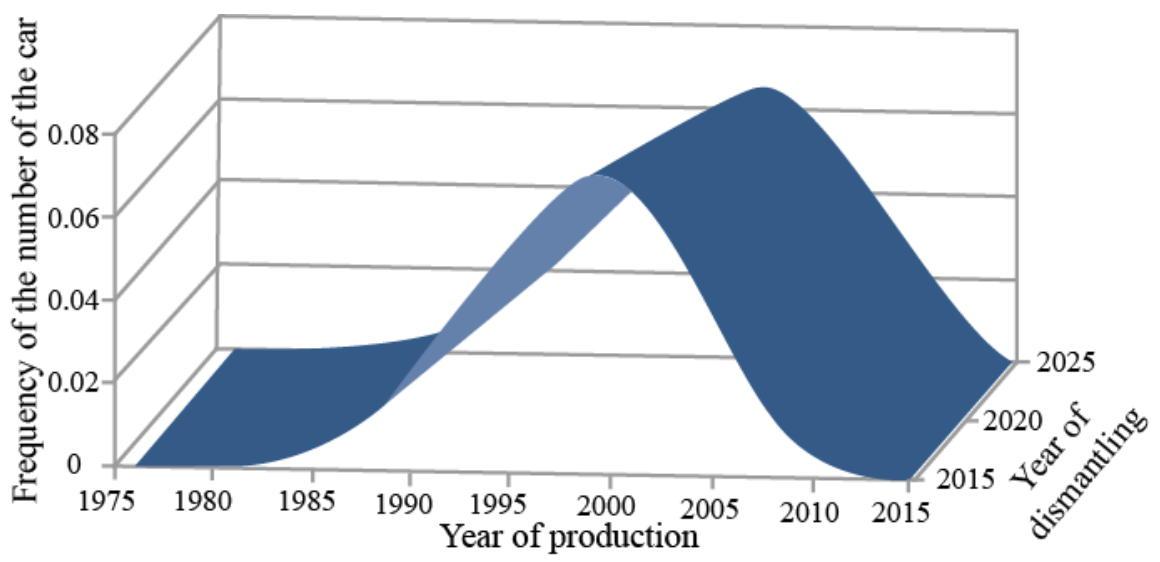

Figure 5

The distribution of the number of ELV, depending on the year of production and the year of dismantling in the forthcoming period

Based on the Fig. 5, we can see that the width of the number of ELV distribution will increase and the shift to the right to higher production years. Maximum number of ELV will decline slightly over time, as could be expected based on the trend of increase in the parameter (b).

An estimation of the quantity of materials obtained by recycling of the ELV, can be obtained by determining the trend of the most prevalent car models at the end of the life cycle and the amount of materials within those models. According to the Serbian Ministry of Interior Affairs, the most common brands of cars were Zastava, Opel and Volkswagen. The trend of the ELV share for domestic brand Zastava and other unregistered cars in the period between 2003 and 2008 year is shown in Table 1.

Table 1

Share (in \%) of unregistered cars "Zastava" and others in the period since 2003 to 2008 year [24]

\begin{tabular}{|l|l|l|l|l|l|l|}
\hline Brand/Year & 2003 & 2004 & 2005 & 2006 & 2007 & 2008 \\
\hline Zastava & 58.76 & 52.68 & 59.69 & 60.87 & 50.47 & 48.34 \\
\hline Others & 41.24 & 47.32 & 40.31 & 39.13 & 49.53 & 51.66 \\
\hline
\end{tabular}

Trend of the share of ELV which will be recycled in the forthcoming period can be determined according to Table 1 (Fig. 6). Domestic brand of cars "Zastava" has been stopped production since the end of the 2008 year, it is logical that their share in the forthcoming period of recycling will rapidly decrease. 


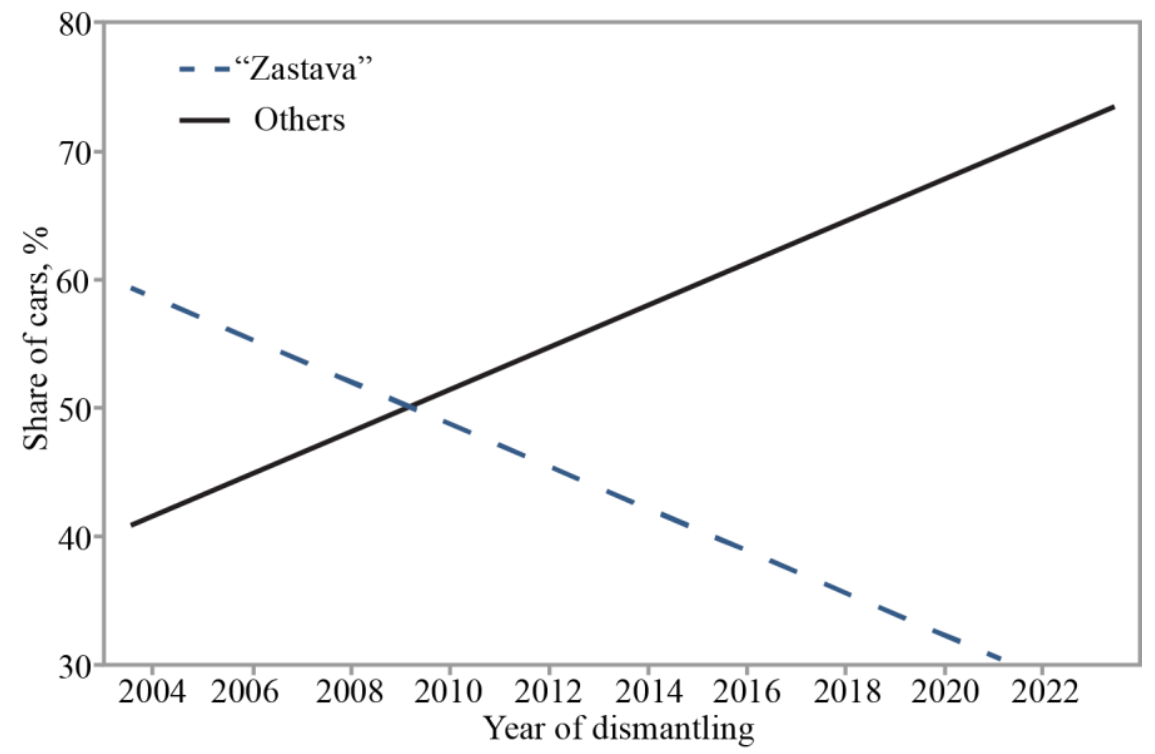

Figure 6

Trend of the share of unregistered cars "Zastava" and others in the forthcoming period in Serbia

The distribution of materials in cars Zastava and Opel Astra are given in Table 2.

Table 2

Share of materials in the car Zastava and Opel Astra

\begin{tabular}{|c|c|c|c|c|}
\hline Material & \multicolumn{2}{|c|}{ Zastava } & \multicolumn{2}{c|}{ Opel Astra } \\
\cline { 2 - 5 } & $\begin{array}{c}\text { Weight } \\
(\mathrm{kg})\end{array}$ & $\begin{array}{c}\text { Share } \\
(\%)\end{array}$ & $\begin{array}{c}\text { Weight } \\
(\mathrm{kg})\end{array}$ & $\begin{array}{c}\text { Share } \\
(\%)\end{array}$ \\
\hline Steel/iron & 626 & 75.00 & 681 & 63.61 \\
\hline Other metals & 48.9 & 5.86 & 89 & 8.33 \\
\hline Plastics & 41.7 & 5.00 & 185 & 17.25 \\
\hline Pneumatics & 25.9 & 3.10 & 30 & 2.82 \\
\hline Glass & 30.9 & 3.70 & 31 & 2.85 \\
\hline Fluids & 15.4 & 1.84 & 17 & 1.61 \\
\hline Rubber & 8.3 & 1.00 & 17 & 1.61 \\
\hline Other & 37.9 & 4.50 & 20 & 1.92 \\
\hline Totally & 835 & 100 & 1070 & 100 \\
\hline
\end{tabular}

According to these data, we can determine the total amount of waste material from cars that will be generated in the period between 2003 and 2023 year, with the approximation that the materials composition of other cars corresponds to the material composition of Opel Astra car as the dominate brand. Together with a simulation of the ELV number in the forthcoming period from Fig. 5, a diagram of the material amount prediction in dismantling year can be constructed. 


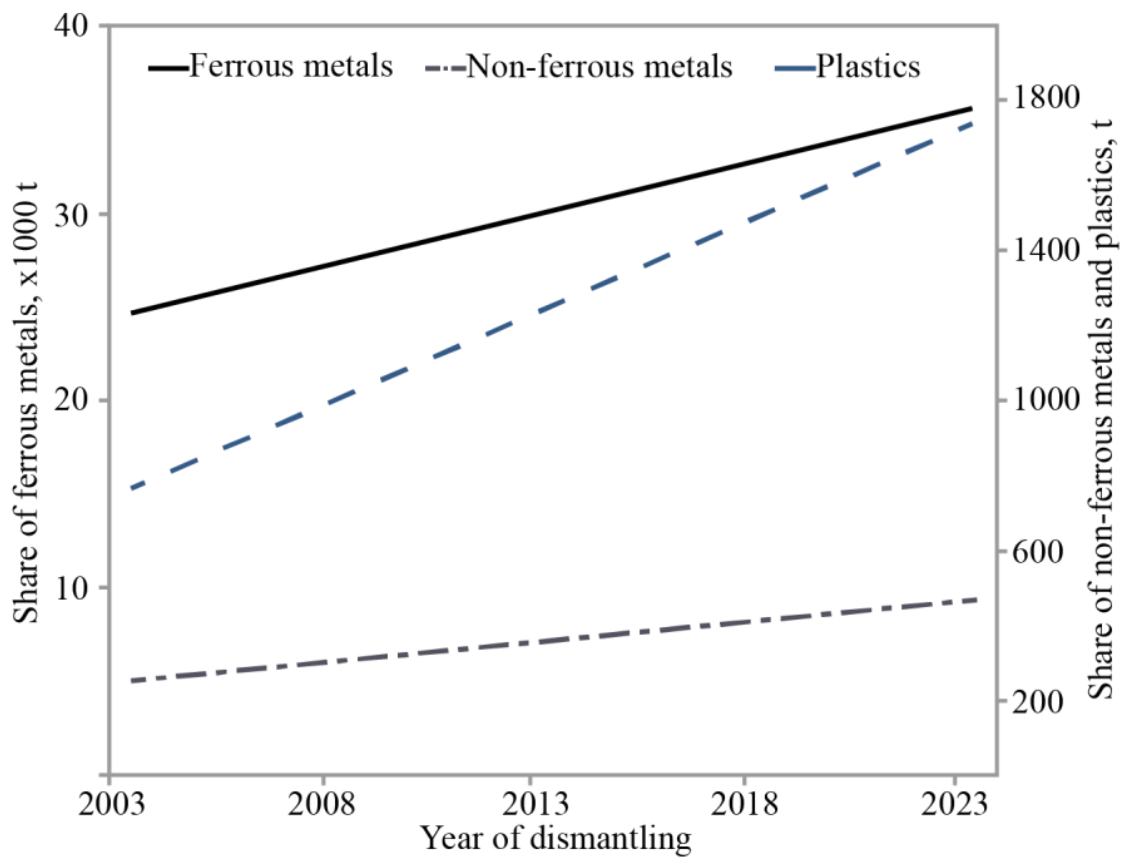

Figure 7

Predicting the amount of material per year of dismantling in Serbia

According to the diagram in Fig. 7, we see that the slope in plastic materials is the largest and the smallest is in non-ferrous metals. For ferrous metals, we also notice a growing trend, which is a result of an increase in the share of the foreign cars that have higher weight than domestic cars "Zastava".

\section{Conclusions}

The recycling industry in Serbia is in a growth stage, thus monitoring and forecasting of ELV is very important. Dismantlers, shredders, metal preprocessors and other related companies within the recycling industry must plan their business based on these data. Accuracy of the forecasting model depends on accuracy of real time data and simulation methods used for forecasting. The twoparameter, Weibull distribution function has been proven to be valid for fitting with the data of ELV distribution, in the past period, as well as, for forecasting of ELV which will generate within the 10 year period between 2015 and 2025 . Results show that distribution of the ELV, in particular year of dismantling, will be spread and shift with regard to the higher year of their production.

The unstable socio-political situations in the country, in previous years, and the impact of domestic car production intensity, have been presented as the most influential parameters for the number of ELV and overall materials in ELV. The overall materials from ELV in year of dismantling obtained from the simulation of 
the ELV in future period and from distribution of the most common types of cars in Serbia, indicate that plastic material have a higher growth rate, from $800 \mathrm{t}$ (in 2003 ) to $1800 \mathrm{t}$ (in 2023). Also, ferrous materials have a significant growth rate, from $25 \mathrm{kt}$ (in 2003) to $35 \mathrm{kt}$ (in 2023), due to the changes in the distribution of car types, in a particular dismantling year. Further work should be focused on simulating the various factors such as Weibull parameters and the distribution of the most common types of cars in Serbia in order to obtain different and more accurate forecasting models.

\section{Acknowledgement}

The authors wish to acknowledge the financial support from the Ministry of Education and Science of the Republic of Serbia through the projects TR34023 and TR35033.

\section{References}

[1] I. Ilić , Z. Gulišija, M. Sokić, Recycling of Metallic Secondary Raw Materials, ITNMS, Belgrade, 2010 (in Serbian)

[2] Directive 2000/53/EC. Commission of the European Communities, directive 200/53/EC of the European Parliament and the council on end of life vehicles. Off J Eur Union, Brussel (2000)

[3] V. Simić, B. Dimitrijević, Risk Explicit Interval Linear Programming Model for Long-Term Planning of Vehicle Recycling in the EU Legislative Context under Uncertainty, Resour. Conserv. Recycl., 73, 197-210 (2013)

[4] M. B. G. Castro, J. A. M. Remmerswaal, M. A. Reuter, U. J. M. Boin, A Thermodynamic Approach to the Compatibility of Materials Combinations for Recycling, Resour. Conserv. Recycl., 43, 1-19 (2004)

[5] M. A. Reuter, U. J. M. Boin, P. Rem, Y. Yang, N. Fraunholcz, A. Van Schaik, The Optimization of Recycling: Integrating the Resource, Technological, and Life Cycles, JOM, 56, 33-37 (2004)

[6] J. Staudinger, G. A. Keoleian, M. S. Flynn, Management of End-of-Life Vehicles (ELVs) in the US, Report for Japan External Trade Organization (JETRO). University of Michigan Center of Sustainable Systems, Report No. CSS01-01, Ann Arbor, MI (2001)

[7] D. Klempner, K. Frisch, B. Pokorski, V. Sendijarevic, Characterization of Various ASR Streams, SAE Technical Paper 1999-01-0670, doi:10.4271/1999-01-0670 (1999)

[8] Y. W. Cheng, J. H. Cheng, C. L. Wu, C. H. Lin, Operational Characteristics and Performance Evaluation of the ELV Recycling Industry in Taiwan, Resour. Conserv. Recycl., 65, 29-35 (2012) 
[9] A. Bustani, P. Mackay, E. Cobas-Flores, S. Yester, J. Sullivan, R.L. Williams, An Approach to Modelling the Vehicle End-of-life Process, SAE Technical Paper 980099, doi:10.4271/980099 (1998)

[10] J. A. Isaacs, S. M. Gupta, Economic Consequences of Increasing Polymer Content for the USA Automobile Recycling Infrastructure, J. Ind. Ecol., 1, 19-33 (1997)

[11] J. E. Boon, J. A. Issacs, S. M. Gupta, Economic Impact of Aluminum Intensive Vehicles on the USA Automotive Recycling Infrastructure, J. Ind. Ecol., 4, 117-134 (2000)

[12] J. E. Boon, J. A. Issacs, S.M.Gupta, End-of-Life Infrastructure Economics for 'Clean Vehicles' in the United States, J. Ind. Ecol., 7, 25-45 (2003)

[13] Siavash Sadeghi, Mojtaba Mirsalim, Arash Hassanpour Isfahani, Dynamic Modeling and Simulation of a Switched Reluctance Motor in a Series Hybrid Electric Vehicle, Acta. Polytech. Hung., 7, 51-71 (2010)

[14] P. Zamudio, Economics of Automobile Recycling. MIT MS Thesis, Boston, MA (1996)

[15] A. P. Bandivadekar, V. Kumar, K. L. Gunter, J. W.Sutherland, A Model for Material Flows and Economic Exchanges within the USA Automotive Life Cycle Chain, J. Manuf. Syst., 23, 22-29 (2004)

[16] P. Ferrao, P. Nazareth, J. Amaral, Strategies for Meeting EU End-of-Life Vehicle Reuse/Recovery Targets, J. Ind. Ecol., 10, 77-93 (2006)

[17] P. Ferrao, J. Amaral, Assessing the Economics of Auto Recycling Activities in Relation to European Union Directive on End of Life Vehicles, Technol. Forecasting Social Change, 73, 277-289 (2006)

[18] J. Amaral, P. Ferrao, C. Rosas, Is Recycling Technology Innovation a Major Driver for Technology Shift in the Automobile Industry under an EU Context?, Int. J. Technol. Policy Manage., 6, 385-398 (2006)

[19] V. Kumar, J. W. Sutherland, Achieving Higher Material Recovery Rates from End-of-Use Vehicles, Trans of NAMRI/SME, 35, 201-208 (2007)

[20] V. Kumar, J. W. Sutherland, Sustainability of the Automotive Recycling Infrastructure: Review of Current Research and Identification of Future Challenges, Int. J. Sustainable Manuf., 1, 145-167 (2008)

[21] C. A. Tsiliyannis, Internal Cycle Modelling and Environmental Assessment of Multiple Cycle Consumer Products, Waste Manage., 32, 177-193 (2012)

[22] A. Van Schaik, W. L. Dalmijn, M. A. Reuter, Impact of Economy on the Secondary Material Cycle, Proceedings COM Waste Processing and Recycling in Mineral and Metallurgical Industries IV, Toronto, Canada, 2001, pp. 407-423 
[23] A. Van Schaik, M. A. Reuter, U. M. J. Boin, W. L. Dalmijn, Dynamic Modelling and Optimization of the Resource Cycle of Passenger Vehicles, Miner. Eng., 15, 1001-1016 (2002)

[24] A. Van Schaik, M. A. Reuter, The Time-Varying Factors Influencing the Recycling Rate of Products, Resour. Conserv. Recycl., 40, 301-328 (2004)

[25] Ministry of Internal Affairs of Serbia., Data on Registration of Motor Vehicles in Serbia for the Period of 1998 to 2008. In: Belgrade, Serbia, (2009) 